\title{
EL LENGUAJE VANGUARDISTA EN LA POESÍA DE JUSTO ALEJO
}

\author{
Manuel Ángel Delgado de Castro \\ madelgadodc@yahoo.es
}

\section{RESUMEN}

Se pretende demostrar el carácter vanguardista de la poesía de Justo Alejo a través de: a) los componentes del signo lingüístico y de la lengua oral, mediante la ruptura de la palabra, levantando letras y sílabas, para potenciar su valor comunicativo y su contenido simbólico, utilizando recursos literarios y pragmáticos; junto a una original concepción del poema visual desde la maquetación tipográfica a la imbricación de la imagen en el texto verbal; y b) el compromiso ético y la crítica socioeconómica a partir de los textos resultantes.

PALABRAS ClAVE: vanguardia; pragmática; compromiso; crítica

\section{Abstract}

It aims to demonstrate the avant-garde poetry Justo Alejo through: a) the components of sign language and spoken language, by breaking the word, raising letters and syllables, to enhance their communicative value and its symbolic content using literary and pragmatic resources; with an original conception of visual poem from the typographic layout to the overlapping of the image in the verbal text; b) ethical commitment and socioeconomic criticism from the resulting texts

KEYWORDS VANGUARD; pragmatic; commitment; criticism

Este artículo forma parte sustancial de la tesis, La poesía de Justo Alejo: vanguardia y sociedad, elaborada por el mismo autor del artículo en la Universidad Nacional de Educación a Distancia (UNED) 


\section{UN REPASO A LA VANGUARDIA PARA PRESENTAR A JUSTO ALEJO}

Cuando hablamos de vanguardia o de modernidad, hay que hablar de Baudelaire ${ }^{1}$ y del siglo XIX, porque este poeta — y pensador — abrió la puerta a la inclusión de la ciudad como demarcación y terreno propio para la poesía desde entonces. Y no solo la ciudad sino las relaciones entre los hombres que viven en la ciudad, o mediatizados por ellas, que se desprenden de los vínculos sociales que se llevan a cabo en las ciudades, serán el eje fundamental de los temas y motivos de la poesía de los siglos XIx y xx, y de estos inicios del XxI. Dice Baudelaire (1985:6) en el prólogo de los Pequeños poemas en prosa:

¿Quién no ha soñado el milagro de una prosa poética, musical, sin ritmo y sin rima, tan flexible y contrastada que pudiera adaptarse a los movimientos líricos del alma, a las ondulaciones de la ensoñación y a los sobresaltos de la conciencia? Esta obsesión nace de frecuentar las grandes ciudades, del entrecruzamiento de sus incontables relaciones.

También la presencia o ausencia de la ciudad y esas relaciones serán motivo de múltiples y variadas creaciones literarias; y su cuestionamiento, la vivencia al margen de la ciudad o en contra de ella, abocará a los poetas al solipsismo y la marginalidad. Un proceso que culmina Mallarmé con "la equiparación de teoría y praxis sobre los principios desarrollados por Baudelaire de una forma radical" según Cózar (1995).

Igualmente Walter Benjamin en el Libro de los pasajes (2005) retrotrae al siglo XIX los inicios de la modernidad literaria, escogiendo a Baudelaire (2005:46, 57-59) en la poesía, entre otros ejemplos en la prosa, para constatar y determinar la fuerte irrupción del sistema social burgués e industrial que se desarrollará desde entonces mediatizando la vida de los seres humanos que están inmersos en su dinámica y su vorágine. Comenta Tiedemann (2005:21) en el prólogo al Libro de los pasajes:

El destino de la cultura en el siglo XIX no fue otro que precisamente su carácter mercantil, que según Benjamín se representaba como fantasmagoría en los «bienes culturales». Fantasmagoría, espejismo, engaño es ya la mercancía misma, en la que el valor de cambio o la forma del valor en sí encubre el valor de uso; fantasmagoría es el proceso de producción capitalista en conjunto, que se enfrenta como una potencia natural a los hombres que lo llevan a cabo. Lo que según Benjamín expresan las fantasmagorías culturales — «la ambigüedad característica de las relaciones y productos sociales de esta época»—, es lo que también determinaba en Marx «el mundo económico del capitalismo»: una ambigüedad que «resulta claramente visible en las máquinas que agudizan la explotación en vez de aliviar la suerte del hombre».

Dos escritores cuyo acierto al encajar literatura y sociedad como base o sustento de la modernidad literaria hasta nuestros días, los hace confluir con Alejo y nos permite ordenar la

1 "De hecho es Baudelaire quien mejor sintetiza en sus ideas los rasgos principales de la modernidad, que Mallarmé representa a su vez con su obra. El concepto de modernidad, formulado en el año 1859, y sus ideas estéticas (Curiosités esthétiques y L'art romantique) desarrollan los rasgos básicos de nuestro siglo: la despersonalización de la lírica moderna; la concepción del arte como investigación sobre el lenguaje; la supremacía de la forma; el concepto de anormalidad, de rareza, de absurdo; el hermetismo y la oscuridad; la separación entre el autor y el lector; el papel del poeta como iluminado, como vidente; el rechazo de la realidad y la concepción del arte como construcción de una nueva realidad irreal mediante el sueño y la fantasía”. Cózar, Rafael de, (1995). 
obra del sayagués en base a los dos criterios que consideramos fundamentales en su poesía: la creatividad y el compromiso.

En un plano social durante los siglos XIX y xx la vida del ser humano en sociedad se intensificará haciendo que las relaciones se conviertan de meros contactos sociales, cada vez más superficiales por la rutina de la vida diaria, en otros donde la funcionalidad - y la prisa- harán que lo más importante sean las relaciones económicas; pero bajo unas normas y unas leyes que determinarán la burguesía en un plano social y ciudadano, y las empresas en un plano económico. Privada o pública, rural o urbana, la cotidianidad de ese sistema social inundará las relaciones humanas y la ausencia de ellas, o su marginalidad también. Y por ende en el poeta y en su obra. ${ }^{2}$

Todo ello llevará al predominio, cuando no al triunfo — necesario- de las apariencias, la producción y el valor-precio de la mercancía, y, desprendiéndose de ello, la propaganda, la publicidad, aireadas por los medios de comunicación que actuarán de altavoz, de soporte y aparente contrapoder, para convertirse, en definitiva, a lo largo del siglo xx en un instrumento esencial del poder (tanto social — político- como económico) a través y a partir de la palabra, donde el mensaje es el medio, recordando a Marshall Mcluhan con el desarrollo ilimitado de la tecnología, y el modo de someter a las masas en que han devenido los individuos (Benjamin, 2005: 449-450). Efectivamente la prensa, el cinematógrafo y la radio junto a las grabaciones discográficas y más tarde la Tv (y hoy la telefonía móvil e internet), serán un espejo de ida y vuelta donde la sociedad recogerá y/o emitirá sus impulsos de todo tipo. ${ }^{3}$ Nuestro poeta llevará a cabo la plasmación real de esos elementos y su transcendencia, junto a un compromiso social o político en su obra literaria. ${ }^{4}$

Justo Alejo se nutrirá literaria y socialmente de ambas fuentes mencionadas: de Baudelaire tomará no solo el hombre que mira la ciudad sino que hará suya la preferencia del francés por los marginados y la marginación, y su combativa disconformidad con ello; y de Benjamin (2005: 559-560) aprovechará su análisis de la producción capitalista que conduce a un cierto nihilismo, en la representación continua de lo mismo ${ }^{5}$, y la importancia de la publicidad para desenmascarar la falsa realidad que esta presenta con un único interés comercial, aprovechando la imagen icónica, la fantasmagoría y la mímesis benjaminianas (interpretadas en el presente), a través de la ruptura de los mensajes publicitarios.

${ }^{2}$ Comenta Serra, F. (2006:160), que para Benjamin "La política del hombre en la multitud es la del individuo que, cansado de las grandes construcciones políticas [...], se sumerge en la política de lo cotidiano, que pretende "cambiar la vida" antes que cambiar la "gran política"

3 "La cualidad fetichista que adquiere la mercancía afecta a la misma sociedad productora de mercancías, no ciertamente como ella es en sí, sino tal como continuamente se imagina a sí misma y cree comprenderse cuando se abstrae de que precisamente produce mercancías. La imagen que de este modo produce de ella misma, y la que suele intitular como su cultura, corresponde al concepto de fantasmagoría (que es siguiendo a Wiesengrund) «como un bien de consumo en el que nada debe recordar cómo llegó a ser»” Benjamin (2005: 680-81)

${ }^{4}$ Nos sirve como ejemplo la obra, que edita el propio poeta a ciclostil o fotocopia como muestra además de la presencia de la tecnología en la literatura, HOY en día El desencanto LAVA Más BLAAANCO (1976), y del que hay un estudio sobre sus vínculos sociales y económicos en Frühbeck Moreno (2003).

${ }^{5}$ Uno de los libros de Alejo donde retrata críticamente a la sociedad se titula precisamente Separata de Lo Mismo (1974) 
Pero el método de Alejo de romper las palabras destacando semántica y semióticamente ciertas letras y sílabas, también será deudor de Rimbaud, o Verlaine, por la potencialidad que le otorga Alejo en ocasiones a las vocales y los colores; así mismo en sus versos se reflejarán la conceptualización y el silencio resultante de la composición tipográfica de Mallarmé, y la visualización de este, de Apollinaire y del dadaísmo; beberá de las asociaciones fonéticas y fonológicas de este movimiento y del creacionismo; y del surrealismo tomará además la ruptura sintáctica con el fin, quizás, de romper metafóricamente del mismo modo la sociedad. Aunque nada de todos los elementos mencionados será útil para el poeta sayagués sin la necesaria colaboración de la ética, que encuentra en César Vallejo y Antonio Machado principalmente, que aglutinará dichos elementos y les dará el sentido fundamental que hará de la poesía de Justo Alejo la obra personalísima de un poeta que reúne vanguardia, ética y compromiso social como eje esencial de su poesía.

Y si añadimos la poesía pura, de Valery a Jorge Guillén pasando por Juan Ramón Jiménez, la creatividad simbólica de las imágenes de Lorca, le sumamos el componente pop y underground, más la plasmación sobre la vida cotidiana del lenguaje (coloquial) de la publicidad, ya en la década de los años 60 de la que los novísimos de Castellet son una muestra, solo faltará colocar la guinda conceptual de los agujeros de Francisco Pino, para encontrarnos delante de la complejidad del mundo poético de Justo Alejo, que este irá desgranando en su obra con su gran creatividad a partir, básicamente, de los dos componentes del signo lingüístico saussureano y el apoyo de la lengua oral, desarrollando de esa manera junto con la semiótica y la pragmática, todos los rasgos importantes que podemos distinguir en la poesía del poeta sayagués.

\section{LA VANGUARDIA EN EL LENGUAJE POÉTICO DE JUSTO ALEJO}

La creatividad lingüística en el terreno vanguardista que desarrolla Justo Alejo en su poesía se apoya formalmente en la cotidianidad, es decir en la lengua oral que se encuentra a diario en la sociedad española de aquellos momentos finales del franquismo, y con el lenguaje de los anuncios instantáneos de una cafetería, del metro madrileño, de la publicidad, de la Tv o del rico acervo cultural de expresiones y refranes. En cuanto al fondo su creatividad reflejará una intención de compromiso social con el común de los españoles, donde el humor o la ironía en su poesía, se darán la mano con la denuncia de la especulación, el sometimiento sutil a la Tv ya sea por sus directrices o por el mero entretenimiento alienante, o la crítica de la aceptación sin cuestionamientos de la publicidad.

Su estilo literario como todo auténtico innovador se apoya en la tradición ${ }^{6}$, cuyo modelo al principio son principalmente los clásicos españoles del siglo de Oro, para centrarse enseguida en la poesía contemporánea, primero de habla hispana y con posterioridad europea. Con respecto a la lengua, tanto en su sentido oral como escrito, es en su tierra donde descubre sus vínculos comunicativos con el hombre en sus raíces sociales y paisajísticas para llegar más tarde a la ciudad y al deslumbrante mundo moderno, y por último a la reflexión donde el poeta

6 “( $\mathrm{Su}$ ) postura (está) más allá de la postura esteticista o la poesía realista convencional”. Rozas, J. M. (1986:139) 
zamorano envuelve sentimiento y pensamiento con las posibilidades de un lenguaje, pleno ya de conocimiento y estudio, que desarrollará su creatividad.

Como poeta oscila en sus comienzos entre la poesía pura, la ingenua, la humorística y la social [...] La veta tradicional se combina ya con la vanguardia — en la línea de César Vallejoen Desde este palo y Alaciar [...] Pero es en el libro siguiente, SERojos luNARES (1969) donde impera ya totalmente el vanguardismo. (Paraíso, 1990:181)

Y estando a caballo entre las dos generaciones poéticas importantes de la segunda mitad del siglo xx, su modo de hacer poético se decanta, sin abandonar nunca el compromiso que caracteriza la poesía social, en la llamada generación de los novísimos, con quienes coincide en la parafernalia de la ciudad, ${ }^{7}$ en el uso de la publicidad, en el cuidado por el lenguaje, cierto culturalismo en los textos, el coloquialismo, un lenguaje urbano... Unas coincidencias sin embargo que solo parecen estar en compartir un mismo marco cultural y sociológico, ${ }^{8}$ aunque no en desplazar lo fundamental a lo anecdótico. ${ }^{9}$ Lo nuevo en realidad será ver la tradición con otros ojos.

Pero para un estudio comprensivo de los factores que intervienen en el quehacer creativo creemos conveniente dividir su poesía vanguardista en cinco apartados: I- La ruptura de la palabra. II- La lengua oral. III- La distorsión de la semántica en la palabra. IV- La distorsión de la semántica en la sintaxis. V- El lenguaje visual.

\section{1. La ruptura de la palabra}

Encontramos uno de los modos de expresar la vanguardia en el alzamiento con mayúsculas de letras o sílabas (incluso palabras), llamando la atención sobre las mismas y destacando de esa manera el significado aislado de esas letras o sílabas. Pero es este un comportamiento que de hecho también añade otro significado a toda la palabra, o, en ocasiones, lo superpone al propio de la palabra a la pertenecen esas letras o sílabas levantadas. Así en el poema «eros y...» de sola- / MENTE /unas /PALABRAS... encontramos en los versos finales una alusión a la Eva bíblica, que tiene sus propias connotaciones eróticas que también aprovecha el poeta, que está incrustada en el interior de las palabras que usa en el poema: "y se EVAde / y nos llEVA", donde el significado de Eva no nos hace olvidar el propio de la palabra que comporta y se acomoda, junto a los significados superpuestos, incluido el simbolismo del color tierra, en la grafía, para evocar el paraíso terrenal, con todo el poema. O en «anaTEMA A LA emPRES.A. anunCIAdora», título de un poema del librito monuMENTALES REBAJAS... que dedica el poeta al rastro madrileño, donde al quedar levantadas "PRESA", "S.A." y "CIA", incluye con/en "PRESA" el sentido

${ }^{7}$ Moral, C. G. y Rosa Ma Pereda (1982) comentan entre las características (1982: 30) de la poesía de los novísimos, el collage (1982: 32) o los grafitis (1982: 35), que podemos considerar cercanas al poeta sayagués.

8 "Una historia de la poesía de la generación del 70 [...] debería, partir del análisis del marco sociológico y cultural [...] no como una cadena temporal [...] sino como una malla donde todas las piezas se articulan, cruzando los discursos en un presente contradictorio pero unitario". Talens (1989: 123).

9 "(se desplazaba) lo problemático desde lo fundamental — la escritura — a lo anecdótico — los temas y el utillaje retórico-. De ahí el uso político, por ejemplo, de Concha Piquer en la poesía de Vázquez Montalbán podía ser recuperado como una manifestación de un cierto gesto de lo camp y la cultura del kitsch.” Talens (1989: 119-120). 
"depredador" de una empresa; y duplicando las referencias a la empresa esta vez en el sentido des-personalizador que denota lo anónimo en "S.A.", "CIA" (y quizás con veladas referencias a la agencia gubernamental norteamericana), aparte del significado que se despende de la lectura lineal de la frase. E incluso se observa ese doble — o añadido — significado en el propio título del libro donde Alejo destaca la relación con la mente y por extensión el pensamiento, aplicado al anuncio, que utiliza y manipula el poeta sayagués para resaltar el efecto alienante de la publicidad a través del mensaje que deja en las mayúsculas: "MENTALES REBAJAS". Por otro lado el uso de las siglas le ofrece a Alejo un mecanismo de levantamiento de letras que ya está en la lengua, y que denota un cierto alejamiento del ser humano de la lengua, aprovechado por el poeta sayagués en ese anonimato u orfandad que deja a la palabra sin el referente claro de la realidad. Entre otros ejemplos lo utilizará el poeta sayagués con las siglas que expresan auxilio - S.O.S. - formando parte de una palabra que tiene su propio significado. Así en un poema dedicado a un poeta desconocido, Genaro Vicario, de El aroma del viento escribirá "ingentes / ver S.O.S. / que no podían con su alma", expresando esa petición de auxilio, vinculada a sus versos y su poesía, como al propio poeta, que están necesitados de lectura. Hay otros ejemplos como la $o$ final de palabra, que se convierte visualmente en un cero, con la expresión conceptual y simbólica de vacío, de nada, o de rotundidad semántica intensificando de esa manera el significado de la palabra que la porta. Así en el poema de Son / netos /// son ecos «Tú no eres piedra ni de piedra Pedro» donde señala con mayúsculas las oes finales de palabra y de verso de muchos de

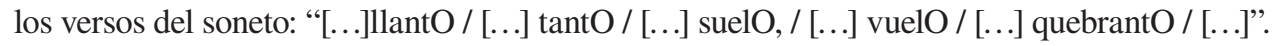

Son aparentes recursos lingüísticos pero que intensifican el significado de la palabra que los soporta con esa llamada visual, donde el sentido simbólico tiene cabida como recuerda Díaz Rojo (2002):

La facultad evocadora de conceptos abstractos atribuida al fonosimbolismo de los sonidos del lenguaje no radica en una supuesta capacidad intrínseca de los fonemas — muy difícil de demostrar-, sino que es el producto de diversos mecanismos semánticos a través de los cuales los sonidos o significantes se cargan a posteriori de ciertas connotaciones añadidas. [...] En consecuencia, concebimos el fonosimbolismo como la evocación de un concepto por medio de un sonido, pero no de forma directa, sino como resultado de la previa intervención de otros fenómenos basados en la transferencia semántica

... y donde como hemos podido ver Alejo recompone o recrea incluso recursos literarios añadidos. ${ }^{10}$ Huellas palpables, de una u otra forma, del juego de palabras del dadaísmo o el creacionismo, de las posibilidades del letrismo, y del aporte conceptual y simbolista sobre la poesía alejiana de Valery y Mallarmé.

\section{2. La lengua oral: entonación, pragmática, uso popular...}

Sin duda los recursos vanguardistas de Alejo se valen de la materia física del lenguaje, pero es esencialmente necesaria la anuencia y colaboración del significado que queda sobre las palabras que utiliza el poeta sayagués para mostrarnos más facetas del lenguaje cotidiano,

${ }^{10}$ No debemos olvidar sin embargo el sentido visual, que tiene este recurso alejiano de levantamiento de letras y sílabas, como en otra medida sonoro, sobre los que volveremos. 
más completas y críticas, como dice Vázquez Montalbán (1972) en Triunfo: “[...] los poemas de Justo Alejo son quizá la respuesta más radical que formalmente se ha hecho en España al lenguaje de los mass media".

Justo Alejo da a la entonación una significación que utiliza a partir de la lengua oral como es lógico. Pero la quiere expresar de manera que resalta un sentido visual significándolo en la tipografía. Como en el verso del poema «LOSA en la IUNA» de SERojos luNARES : "[...] Me hablablablablababa de aromas de doncellas sin olerlas [...]", donde ya la expresión gráfica alude, físicamente, al blablablá de hablar por hablar, coincidiendo la connotación, valorada en términos sociológicos, con el uso de la implicatura de la pragmática.

También expresará la entonación a través de la grafía prolongando letras; por ejemplo en el poema «Nítido» de Son / netos..."[...] mientras truena La Voz del ChatarrerooOO [...]”, que imita el sonido real en la tipografía no solo con la prolongación de la vocal $o$, sino marcando además la intensidad de la voz al poner la $o$ a continuación en mayúscula y prolongarla a su vez.

Y usará colores diferentes, como en el interior de un poema sin título de los Doce dulces sonetos..., tal y como los publicó Armero (1990) en la revista del Ministerio de Cultura, Poesía $\mathrm{n}^{\mathrm{o}} 33$, siguiendo las indicaciones del poeta: ${ }^{11}$

\author{
CIAMOROSO, AMOROSO \\ MOROSO, OROSO... \\ y $\mathrm{O}$, es el fraterno $\mathrm{VAHO}$ de \\ lo COTIDIANO \\ cuando se libra del barniz \\ pertinaz de lo corriente
}

AY CALDO

... donde excepto el "AY CALDO" final, todo tiene una tipografía en azul, color cuya simbología podría aportar levedad o suavidad (y en este caso, por similitud semántica, condescendencia del poeta con el gesto cotidiano que reseña, explicándolo y justificando la incorrección ortográfica, haciéndola más humana si cabe), usando de ese modo el color como una muestra de entonación y la vez portador de un valor simbólico y expresivo desde un punto de vista semántico.

La modalidad también tiene cabida en la poesía de Alejo, como en los primeros versos del apartado «VI» de HOY en día El desencanto...:

Y quiSIMOS comprender tantO

llanto, pero no tanto EL DESENCANTO de ESA fracción

social_como tal_"

${ }^{11}$ Gonzalo Armero publica junto a los poemas la carta que el poeta le envió con las indicaciones pertinentes para su edición. 
Son en efecto los rasgos tipográficos los que nos indican el uso, necesario para el poeta sayagués, de los matices que tiene la lengua hablada, como la modalidad en este caso al destacar en negrita "quiSIMOS" y "ESA", evocando un modo gráfico de alzar la voz en las últimas sílabas de "quisimos" levantando "-simos"; e incluso en la "Y" inicial para la que utiliza una tipografía en hueco, dando a entender, para nosotros, de un modo simbólico una entonación ahuecada o más silenciosa ${ }^{12}$.

También aprovecha las posibilidades que ofrecen las funciones del lenguaje, en el poema sin título de monuMENTALES REBAJAS...:

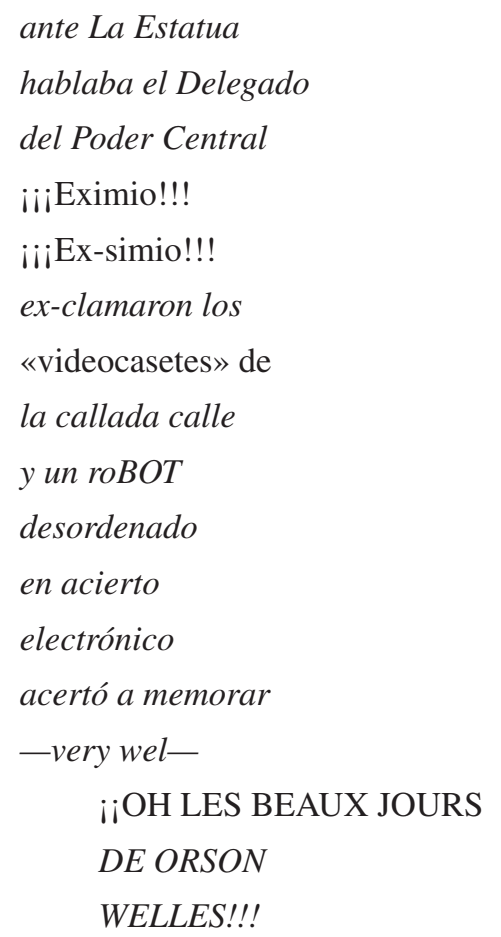

Aquí, en un solo poema esgrime los recursos del narrador-emisor, ya que partiendo de un exceso de entonación del orador al que alude el poema —o de un error de dicción- recrea el texto destacando la información en la introducción de los primeros versos; y resalta la función expresiva en la reproducción de las palabras textuales, la función representativa con la explicación posterior y por último la función expresiva que también es poética a través del comentario del poeta. Aunque envolviendo todo ello se percibe una sutil referencia a una función fática, quizás apelativa, o cuando menos la presencia insinuada del autor que busca la aquiescencia del lector, en un uso abiertamente pragmático de la lengua, según nos muestra en "acertó a memorar", en el entrecomillado de "videocasetes", que insinúa una aclaración, y en el guiño del idioma inglés (un recurso pragmático) o el francés (función expresiva).

\footnotetext{
${ }^{12}$ Es útil y necesario para estos ejemplos tener en cuenta el fonosimbolismo y/o la fonética expresiva
} 
Por lo que respecta al uso popular del lenguaje Alejo se servirá también de la lengua coloquial por un lado, y por otro de las expresiones populares o los refranes.

Así lo vemos en el poema «Obsolescencia I», de Son / netos..., donde la reflexión sobre la soledad y la incomunicación en la gran ciudad le hacen escribir:

\author{
Colgado en el balcón y TAN TRANQUILO \\ veo con TOLDO y TODO a mi alter ego \\ en camiSA y calzONES veraNIEGO \\ cual si con él NO FUERA estar en vilo
}

... donde aparte de la situación de familiaridad y cotidianidad de la escena, se ve la espontaneidad de expresiones coloquiales como... "y TAN TRANQUILO", y "estar en vilo", junto a otras más camufladas en la pragmática, por sugeridas y supuestas desde un terreno sociológico, "cual si con él NO FUERA", aludiendo a la expresión coloquial como si no fuera con él, o "con TOLDO Y TODO", aludiendo a la expresión con todo y eso, que evidencian en apenas un cuarteto un buena muestra de lengua viva.

Unos rasgos, en todo este epígrafe, que recuerdan unos con el uso de los colores a Verlaine, a los novísimos con la referencias fílmicas y el uso coloquial del lenguaje otros, como a Jules Laforgue con la cotidianidad y sus reflexiones, y el creacionismo con apuntes expresionistas en el poema alusivo a la película El desencanto de Jaime Chávarri, síntoma del desengaño que provocó entre los españoles el escaso logro social en los primeros momentos de la Transición política del franquismo a la democracia; sin olvidar los ecos de Baudelaire en ese "ay caldo" de los Doce dulces ... por la ternura que denota con los que se equivocan.

\title{
2.3. La distorsión de la semántica: el significado de la palabra
}

A veces una palabra recoge otro significado distinto del que ya tiene, por intensificación gráfica de una letra, lo que hace que a partir de esa letra podamos leer otra palabra sobre la existente. Así el título del poema «PELUQUERIAL (sic) DE SEÑORAS» de Son / netos..., donde en el neologismo que crea con el sufijo "-al” el poeta sayagués sobre el lexema peluquería, vemos la doble lectura de la palabra que se muestra al resaltar en mayúscula y negrita la letra "E", dejando otra palabra, "ERIAL", que debemos añadir, a modo de implicación semántica, a la lectura de la anterior ya de una manera superpuesta. Al quedar acumulados ambos significados, pone Alejo de manifiesto lo yermo, lo vacío que acompaña —en un puro sentido connotativo - todo lo que acontece en un plano humano en una peluquería de señoras.

Semejante caso encontramos en la denuncia de la especulación inmobiliaria: “[...] ${ }_{i i}$ O C A S O S / de / OCASIÓN!!! / a / PLAZOS / BAH / RA /TO / S [...]", de monuMENTALES REBAJAS..., para expresar que lo barato no es tal sino el modo de los especuladores de aprovecharse de la necesidad o la buena fe, remarcada por el poeta en la banalidad aislada de la queja: "BAH", sobre la incorrección ortográfica. Hace así recapacitar al lector a través de 
una interjección incrustada en la palabra. Recogemos de la reseña crítica que hace Armero (1972: 30-31) sobre este pliego de cordel en Trece de nieve que Justo Alejo es un "[...]poeta underground de nacimiento [...]" por el modo de aprovechar "[...]todo el material de derribo de la publicidad (para)[...] representar un mundo re-edificable en el poema"; y añade "[...] se ha paseado por la ciudad, ha dislocado sus affiches sagrados, los ha mezclado, confundido, engañado y escamoteado para darnos una reelaboración poética en su nueva recopilación. Nada se desprecia. Todo es aprovechable [...]".

Algo semejante a una combinación de letras y sonidos, encontramos en el título de su libro Son / netos /// son ecos, donde el sonido está presente -y encerrado entre el son del inicio, en la portada, y el ecos del final, en la contraportada-. Pero lejos del sentido de juego lingüístico, el poeta sayagués amplía el significado de la palabra por la re-creación que hace del significado — son y soneto - evocado por continuidad de todo el enunciado. Diferente lo vemos en el poema «ANA» de SERojos... "[...] no / sueNA aquel doLOOR / [...]", donde el dolor se transforma, o nos lo insinúa el poeta con la intención de superarlo, en una alabanza. Sin darnos cuenta, llegamos aquí a un recurso literario, ya sea paradoja u oxímoron, a partir de un recurso lingüístico. Una recreación del lenguaje que Vigara Tauste (1998) ha estudiado a propósito del comportamiento de la función metalingüística en el hablante, "[...] cuya conducta metalingüística en el uso del lenguaje (ya sea inconsciente o producto de la reflexión sobre el lenguaje) hace confluir en el texto, desde el fonosimbolismo hasta la simple asociación de los constituyentes de la palabra por sugerencia, etc. [...] como ocurre en los anuncios ya manipulados por el anunciante (Feliz Navidul), o en neologismos con intención crítica (burrocracia, sociolisto) [...]”.

Se trata de un modo de sugerir sin duda, pero también se precisa, desde la sociolingüística a las implicaciones de la pragmática, como en la connotación que provoca un rotacismo, o el cambio — ampliación — de significado por proximidad de sonidos o por evocación, según podemos ver en el poema «OBSOLESCENCIA II» de Son / netos... con los recursos que elabora y recrea a partir de La vida es sueño de Calderón, donde en la sencillez natural de la narración, Alejo hace hablar al propio dramaturgo como un trasunto de sí mismo, y evocar de paso una crítica social a través del control, expresado con la interrogación, a que nos someten las empresas mediante vínculos laborales o sociales, que adquieren incluso la categoría de letales: "He preguntado —en SUEÑOS— ¿Qué nos paS.A.? / Balbuce Calderón: Lago Letal (.) ${ }^{13}$ ", para reconocer los mecanismos de generación del lenguaje poético de Alejo donde la sorpresa muchas veces da la impresión de que no se busca sino que se encuentra... en la propia capacidad creativa del lenguaje, bien desde la cotidianidad de la lengua oral (patente en ese “¿qué nos paS.A.?”), o desde la búsqueda del efecto transgresor desde el estudio o el aprendizaje (en el amplitud de significados e interpretaciones que puede tener "Letal").

${ }^{13}$ Aquí además añade una nota a pie de página (haciéndola formar parte del texto poético como una concepción vanguardista más del poema) donde explica "Lago Letal", y donde aprovecha para sugerir con la palabra "algo" de la explicación un calambur, previo rotacismo, por la formación especular de las sílabas "LA" y "AL": "(.) LAGO o ALGO de Leteo...", en un ejemplo más de recreación sobre otra recreación, como mecanismo de composición poética alejiana. 


\subsection{La distorsión de la semántica: las relaciones paradigmáticas y la sintaxis}

$\mathrm{Y}$ un cambio en las relaciones entre sintagmas, como observamos en «SOL Y EDADES» y «ÓSEA, O SEA», sendos poemas de Separata..., produce cambios en el paradigma por la suma de sustantivos en "SOL Y EDADES" creando una nueva palabra, esta existente en la lengua, pero nueva en el sentido normal y comprensivo de la cadena lingüística esperable; donde la concurrencia de las palabras "sol" y "edades" las hace confluir en una sola, soledades, suprimiendo la "y", y permitiendo/forzando el uso de la grafía en favor del habla. Algo semejante ocurre con la forma en que nos presenta el poeta sayagués "ÓSEA, O SEA", pero mediante el recurso literario de similitud o proximidad, porque le permite, desde una perspectiva sintáctica, insinuar una explicación, con la coma y el calambur. Partiendo del valor semántico/semiótico que tiene la primera de las palabras, "ÓSEA", del título del poema, se da a entender con "O SEA" una explicación, en una clara intención pragmática coloquial, que evidentemente no aparece en el texto del título. Pero sí refuerza e intensifica semióticamente el significado de "ÓSEA”, sugiriendo la explicación con todo el poema.

Otros ejemplos de cambios en el paradigma se producen en "deSASTRERÍA", un cambio ahora de sustantivo a adjetivo a través de un neologismo, pero que mantiene el sentido lógico esperable de la palabra a través de las mayúsculas. Así el sustantivo sastrería se transforma en un adjetivo creado a partir de desastre, aludido en la confusión sintagmática. El resultado es unas "confecciones" que son un desastre. El ejemplo se encuentra en el poema «BARATO, SE LIQUIDA» de monuMENTALES REBAJAS...:

\section{confecciones deSASTRERÍA}

$c a-$

\section{MISERIA}

Son cambios formales que originan un vuelco en el significado de las palabras, como vemos en "camisería", un lugar que convierte el poeta sayagués en "ca" y "MISERIA", donde a través del encabalgamiento se destaca la miseria de la situación que narra Alejo en el poema ya convertida en ética. Cambios que son producto de la manipulación del lenguaje de la publicidad para conseguir un efecto concienciador de ese mundo de apariencias y medias verdades que encierra la publicidad.

Encontramos otros casos de neologismos que más allá de cambios en el paradigma o en las relaciones sintagmáticas, muestran un modo de doblegar el lenguaje para arrancarle mayor expresividad y sensibilidad. Son "ORTOPEDIA", como forma verbal del verbo *ortopediar, en "DEL APARATO QUE NOS ORTOPEDIA", en el poema «EROSION-ES» de Separata de Lo Mismo; o en El Aroma..."dormidizo" (sic) en el poema «Madera y alma»; y el regusto poético del título del poema «Inútil quejadumbre» (sic) del inédito «Luces y Señales», en el cuaderno "Claridad y Distancia" de Poesía 1.

Son juegos con la grafía y la materia sonora y fónica del lenguaje, juegos que recuerdan el creacionismo o la poesía concreta, pero juegos serios por su preocupación social, que desvelan en algún momento la rebeldía, el grito callado o la denuncia social que citábamos en el surrealismo o en los postulados de Walter Benjamin. 


\subsection{El lenguaje visual}

No se trata aquí de considerar la poesía de Alejo simplemente como una poesía visual según las más conocidas muestras de una imagen con sugerencias y/o una expresión simbólica. Para el poeta sayagués debemos tener en cuenta al hablar de poesía visual, la disposición tipográfica de la página y la maquetación del texto en la página; el sentido simbólico de los dibujos, en sí o acompañados del texto formando un todo; la significación de palabras tratando de representar la lengua oral con la grafía, a través de la modalidad y la función expresiva del lenguaje para resaltar la intención poética y comunicativa de Alejo, expresada en huecos y silencios, sin olvidar las mayúsculas; y los agujeros, perforando la página, o la expresión simbólica de los mismos a través de la tipografía, dejando destacadas con mayúscula o negrita las letras $o$ de determinadas palabras, especialmente a final de palabra y de verso.

Ante un panorama tan rico y tan complejo, describiremos los textos poéticos alejianos, sugiriendo solo sus vínculos semióticos, dado el carácter de este artículo, aún a riesgo de quedarnos cortos. Reseñamos así la importancia que tiene precisamente en el terreno de la interpretación para nosotros, las observaciones de Santos Zunzunegui (1994:168-70) para quien hay que valorar la imagen desde un planteamiento cognoscitivo (por las analogías y sugerencias de la imagen) hasta la enunciación visual (con la pragmática como elemento subjetivo constructor). Con sus referencias a Greimas por el uso del análisis (e interpretación) de los signos visuales como sistemas de significación, y sobre todo a Umberto Eco, por la apertura de la imagen al contexto cultural, o su convencionalidad, para llegar a la pragmática y a la cooperación del lector, nos lo hacen también cabalmente importante:

La semiótica introducirá un planteamiento nuevo que se aproxime a pensar el significante como una relación de implicación, haciendo, tanto de la imagen visual como de los fonemas verbales, producciones relacionadas y no equivalentes, interpretaciones, en suma. (Zunzunegui, 1989:112).

Para comprender al poeta zamorano será importante partir de la independencia de ambos signos, el lingüístico y el visual, pero también de su implicación, o su relación metafórica siguiendo a Padin $(1993)^{14}$. La elaboración de las imágenes del texto poético por parte de Alejo es a veces por simple sugerencia personal, ${ }^{15}$ disponiendo una imagen que encaja en el enunciado del poema junto con los signos verbales. Pero al igual que los juegos de palabras con el lenguaje verbal — juegos en el contenido o en la forma (incluso en el forma visual de las palabras) — , hará Alejo con las imágenes en el lenguaje específicamente visual, generando una implicación y complicidad del lenguaje verbal y el no verbal en el resultado final del texto poético. Podemos observarlo en los siguientes poemas de Son / netos /// son ecos y de Separata de Lo Mismo:

${ }^{14}$ Padín, C. (1993) en Dificultades Metodológicas..., habla de "operador visual” y "retórica icónica o visual" vinculada a la lingüística, y de metonimias o metáforas visuales en la poesía, dejando abierto un camino a la interpretación de una imagen visual (entendida en un sentido amplio), con un sentido semántico y sobre todo semiótico, como creemos que hay en la poesía de Justo Alejo.

15 Habla Zunzunegui (1994:169) de la importancia de los aspectos idiolectales de las imágenes. 
Son

Ecos

verS.O.S.

Figura 1. SON ECOS -jarra- verSOS

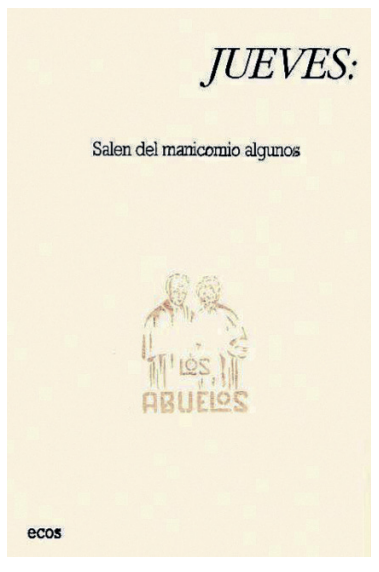

Figura 2. Jueves - Los Abuelos

La implicación de las imágenes parece sugerir en el caso del poema con la jarra el efecto vital refrescante de los versos y por extensión de la poesía. La interpretación nos hace partir de la alusión de las mayúsculas integrantes de la palabra "verS.O.S.", "S.O.S.", que destaca el poeta sayagués como expresión de auxilio. Esa petición de auxilio nos lleva a proponer como interpretación del poema la necesidad de la poesía, de igual modo que es necesaria el agua. Una implicación que establecemos a través de la petición de auxilio "SOS", más el efecto esencial para la vida que tiene el agua, sugerido con la jarra. Apoyándonos en las indicaciones comentadas de Zunzunegui $(1993,1995)$ y Padin (1993) hemos deducido el contexto cultural del agua como parte esencial de la vida, más la implicación pragmática de la llamada de auxilio, a lo que sumamos el enunciado de la lectura de ambos lenguajes, verbal y visual, que solo necesita, por último, la colaboración del lector, para determinar lo esencial de la poesía.

En el caso del poema de los abuelos, interpretamos abuelos como personas mayores, jueves como día de visita, ecos como quejas y manicomio como tal, o mejor como residencia de ancianos. De esa manera el texto nos señalaría las quejas de los ancianos manifestadas el jueves, día de visita; aclarando que quejas puede aludir al trato recibido por los ancianos, o a la soledad que sienten todos los días excepto el día — jueves_ en que algún familiar viene a visitarlos. Así la interpretación - semiótica - que hemos dado se basa en que un día de visita es poco en el cómputo de la semana, y al igual que un eco (una mínima expresión y un reflejo del sonido), es por equivalencia un ejemplo de lo que sienten los abuelos el resto de los días de la semana, que a semejanza del eco se debilita en el tiempo. Se trataría de implicaciones y suposiciones pragmáticas, donde la referencia al tamaño identificada en el tamaño de la letra del jueves y de ecos más el indefinido "algunos", implica que hay más (quejas) que no salen. Un tamaño también relacionado semióticamente con el día de visita, si interpretamos las quejas como soledad, porque es el único día grande en la semana.

Se trata de usar un lenguaje donde también se aprecia la huella de Mallarmé en la disposición tipográfica de la página y la maquetación del texto como en este poema de Son / netos...: 


\section{AHORA \\ TODOS}

a precios intereSANTI-

SIMOS

vea precios en

nuestros escaparates

El lenguaje, además de la crítica social que encierra el propio texto verbal, es una muestra de la manipulación que hace el poeta zamorano del lenguaje de la publicidad con herramientas semejantes a las de este, desde las mayúsculas y su disposición tipográfica a los cartuchos anunciadores, y donde la captación visual del lector es la clave del poema.

La búsqueda de una mayor significación de la palabra tratando de representar la lengua oral con la grafía, a través de la modalidad y la función expresiva del lenguaje, es otra muestra del lenguaje visual de Alejo, como en el poema «Calvicies y florestas» de Son / netos...:

Sobre Aquel CERrO

para in / fraganti la desNUDA OLA

FLORADA

hace sonar

ALGO más SER

$i$

$o \ldots$

... en este caso por el uso que hace de la pragmática para añadir matices de modalidad al texto poético con la función expresiva del lenguaje, en un intento de plasmar la lengua oral sobre el texto escrito con la tipografía en negrita de "in / fraganti"; y con las palabras que quedan en mayúscula, tratando de reflejar de ese modo una manera de alzar la voz, o un tono - llamativo- diferente de la voz, o, como en el último verso, la caída sonora de la entonación al final de una frase, dejando rota la palabra y de paso destacada una parte de ella con la intención de focalizarla semánticamente añadiendo una significación filosófica sobre su resultado, "SER", que coincide con la disposición tipográfica escalonada.

Un sentido pragmático semejante le hace usar el color en la tipografía de sola- / MENTE / unas / PALABRAS... y en Doce dulces sonetos... como hemos comentado más arriba, para algunos poemas donde quiere resaltar con la semiótica la delicadeza en el contenido semántico, la crítica o su vinculación con la naturaleza.

Pero donde el lenguaje visual es más claramente vanguardista es en el uso de los agujeros, que pueden formar parte gráfica de una palabra a través de la letra $o$, o tener una expresión simbólica evidente que no siempre forma parte de un lenguaje verbal, sino fundamentalmente visual e icónico, y por ende semiótico. 
El agujero muestra primariamente la ausencia de letra y de sonido, e incluso ausencia del propio lenguaje. Véase en el poema «puro» de evidentes sugerencias minimalistas de sola- / MENTE...

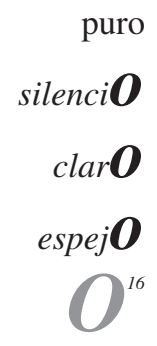

... y en el poema «Homenaje» donde alude el poeta sayagués al juego intelectual y conceptual de orar a Dada (dadaísmo) con unos versos cuyo enunciado escultura ora-dada, que es culto al viento, pueden ser un homenaje o una crítica ${ }^{17}$, y donde la "O" de viento es un agujero de tres cuerpos tipográficos, por donde materialmente puede pasar el viento al estar la página horadada:

Ora-DADA
una escultura
es cultura
o culto
Al
vient $O^{18}$

Motivos y temas que no excluyen ningún contenido, incluido el político como ocurre en el poema que alude al exilio también de sola- / MENTE... En este caso el agujero está solamente dibujado al incluir una "o" dentro de un círculo, en el centro superior de la página, y colocando la palabra «exilio» casi en el centro inferior, de la que desgaja, como en un exilio real, la letra "o" (“EXILI O”). El poema, además, debe leerse con el poema de la página siguiente ${ }^{19}$ donde coloca una "o" en el centro superior de la página, dejando la palabra "solo" con una tipografía grande, en hueco y en color tierra en el fondo inferior izquierda de la página. Termina con un texto entre paréntesis y con una tipografía más pequeña, en la parte inferior derecha, que dice "de viento". La lectura lineal del texto completo que hacemos es "O exilio, o solo", remarcado físicamente por el anverso y reverso de la página, una separación física que, como sucede con el exilio real, no evita que se trate del mismo lugar. Una simbología marcada por los rasgos semióticos que expresan la disposición tipográfica

\footnotetext{
16 Aquí no hay una "O" sino un agujero

${ }^{17}$ El poema, como homenaje puede aludir a alguna de las esculturas contemporáneas que se instalaron en Madrid en la década de los años 70; como crítica aludiría al vacío del dadaísmo.

18 Aquí no hay una "O" sino un agujero.

${ }^{19}$ En un eco más de la doble página del Golpe de dados de Mallarmé (1985).
} 
y el sentido semántico al que remite un exilio por el vacío, la ausencia y la soledad que lleva connotados.

Son unos versos que tienen ecos vanguardistas que podemos encontrar en las primeras vanguardias, tanto por la disposición tipográfica como por los colores o el minimalismo, en Mallarmé, Apollinaire, o el surrealismo, pero también en Francisco Pino o José Miguel Ullán, a quienes conoció y trató el poeta sayagués. Incluso podemos reconocer elementos comunes siguiendo a Sarmiento (1990), con Brossa, "[...] Brossa los toma de su entorno cotidiano [...]" (1990:31), o con Cirlot, "[...] al utilizar la permutación como técnica poética, [...] dejando que el poema se reduzca a una operación de metamorfosis entre sus elementos formales [...]" (1990:32).

\section{LA VANGUARDIA Y EL COMPROMISO (ÉTICO) EN JUSTO ALEJO}

El compromiso ético y social de su poesía es el que cierra su ciclo literario, da sentido a su poesía vanguardista y la hace diferente de otros textos vanguardistas. Hace que la poesía no se quede en la simple referencia semántica del lenguaje sino que sean todos sus componentes comunicativos, como hemos visto, los que le den un sentido pleno e identificativo. Crea de esa manera una crítica que está cercana al hombre, que refleja y se mueve entre hechos cotidianos, y que casi nunca es solamente ideológica, porque Alejo expresa ideas - junto a sentimientos - a través de los hechos diarios que encuentra en la vida cotidiana.

Su lenguaje toma efectivamente de la lengua cotidiana, hablada y coloquial, sus mejores recursos lingüísticos y literarios, entre los que la ironía y el humor aprovechan la potencialidad del lenguaje para expresar más ampliamente ideas y sentimientos. Por otro lado el lenguaje publicitario, junto a los elementos comunicativos que rodean el mundo de la publicidad, permitirá al poeta zamorano desarrollar la crítica social y denunciar la situación del hombre en una sociedad consumista con las mismas técnicas que utiliza el anuncio y el reclamo publicitario.

Aparece este lenguaje primeramente en monuMENTALES REBAJAS... que es desde el título una denuncia de la manipulación de los métodos de las grandes empresas a través de la publicidad, por el modo de bombardear al ciudadano con eslóganes, la incitación al consumo, a veces innecesario para el ciudadano pero rentable por las ganancias que genera para la empresa, comercial, inmobiliaria, o bancaria, a las que procura desenmascarar. También con el título va a aludir Alejo a la crítica, por los resultados, "MENTALES RE$B A J A S$ ", adonde parece conducir esa manipulación de la publicidad a favor de la empresa: seres alienados, que no piensan más que en consumir, convertidos en meros instrumentos al servicio de la empresa y del capital según unos propios intereses comerciales y crematísticos.

Veamos un ejemplo en el pequeño poema sin título cuyo primer verso es "FABULOSAS REBAJAS", de monuMENTALES REBAJAS...: 


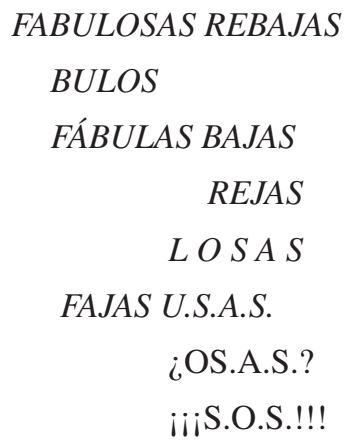

El uso de las mayúsculas y la simple lectura del poema nos dice de donde parte el poeta, “FABULOSAS REBAJAS”, y adonde llega, “iiiS.O.S.!!!”; mientras deja su opinión veladamente camuflada en medio de los versos, como hace un anuncio: "REJAS / LOSAS / FAJAS U.S.A.S." en una clara denuncia, a través de $s u$ propia manipulación, de lo que suponen esas rebajas tan fabulosas. Y donde lingüísticamente pretende Alejo que la aliteración fónica, la anáfora silábica o el paralelismo lleve, por asociación semiótica, al retruécano, la hipálage y en definitiva la crítica.

Como ha expresado el poeta y crítico de arte Amón (1971) en el prólogo a monuMENTALES REBAJAS...:

(Justo Alejo) se vale de la IMAGEN VISUAL, o de los medios que la inflan y expanden, a favor de la publicidad o el control de la expresión dirigida y programada..., pero con el firme propósito de emitir otros contenidos que yacen en su reverso, plenos de validez y CONTRASENTIDO, extraídos de la entraña subconsciente del ciudadano

Veamos otro ejemplo sobre una reproducción digitalizada del texto, por cierto como todo el librito, en rojo llamativo, al modo de los folletos publicitarios. Se trata del poema que cierra la página de «Apuros por la purezA» (dedicado a la pureza de Guillén), y del que destacamos el juego con el lenguaje, sobre el texto publicitario, que hace de los grandes almacenes... sin alma:

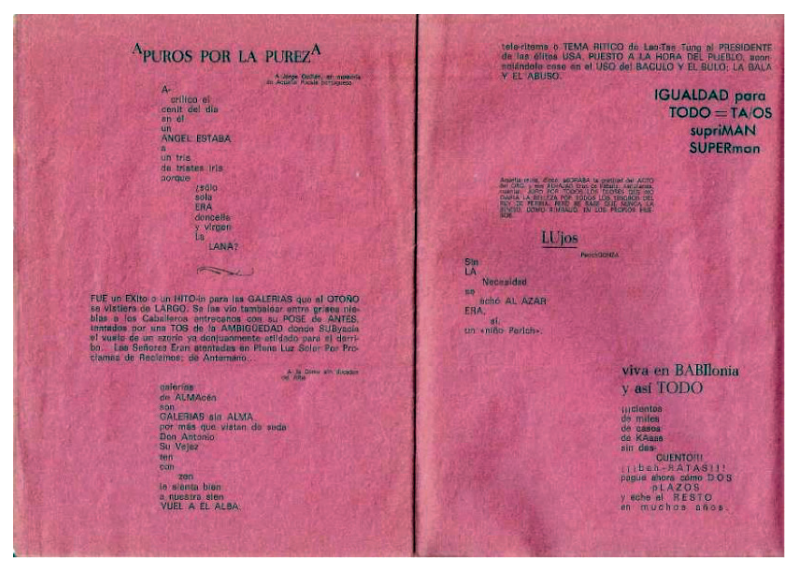

Figura 3. Apuros por la pureza - TAO 
FUE un ÉXito o un HITO-in para las GALERÍAS que el OTOÑO se vistiera de LARGO. Se les vio tambalear entre grises nieblas a los Caballeros entrecanos con su POSE de ANTES, tentados por una TOS de la AMBIGÜEDAD donde SUByacía el vuelo de un azorín ya donjuanmente atildado para el derribo... Las Señoras Eran atentadas en Plena Luz Solar Por Proclamas de Reclamos; de Antemano...

galerías

de ALMAcén

son

GALERÍAS SIn ALMA

por más que se vistan de seda

... donde la presentación en prosa, previa a los versos, recuerda, críticamente, las presentaciones de los desfiles de moda o las crónicas periodísticas de sociedad de la prensa del corazón. Aunque es el juego sobre la palabra "ALMA" y las sílabas semejantes lo que evidencia su crítica social.

Esta "imitación" de la manipulación publicitaria hará que Alejo centre su crítica en las grandes empresas, los grandes almacenes, la banca, las multinacionales... pero deje, en libros posteriores, un hueco para la responsabilidad del ciudadano que se deja alienar, por comodidad o porque se siente, o quiere ser, parte integrante de esa cadena, física y moralmente.

Efectivamente en Separata... y Son / netos... aparecerá un ser humano que ya es parte de ese mundo consumista. Mientras, la crítica contra las empresas será, por contraposición, más evidente y clara, junto a la denuncia ética, haciéndose social e incluso política en el libro que además edita, simbólicamente, a ciclostil o fotocopia, HOY en día El desencanto LAVA Más BLAAANCO. La portada del libro ya denota las diversas técnicas que usa: los cartuchos propios de los anuncios publicitarios, las folletos-anuncios, en este caso de cine, el lenguaje llamativo y visual de la publicidad, y uniéndolo todo el collage.

Dentro del sinfín de todo el texto, que alude simbólicamente quizás a las peroratas de los anuncios (y de los panfletos), se puede apreciar al final del «apartado I» del librito, cómo el poeta destaca la palabra "muebles" en un cartucho-anuncio publicitario, y en el centro de la página se encuentra la imagen, debilitada como una marca de agua, de una mujer sobre la que Alejo escribe el texto "PALABRAS / que son DIOSAS / MITOS / FÁBULAS / MENTIRAS" "20, aludiendo a esa manipulación de la imagen de la mujer, que reproducimos digitalizada para que se vea la composición del texto poético, escalonado, sobre la imagen:

\footnotetext{
${ }^{20}$ Los espacios en blanco hacen alusión a la distinta alineación — escalonada- de los versos.
} 


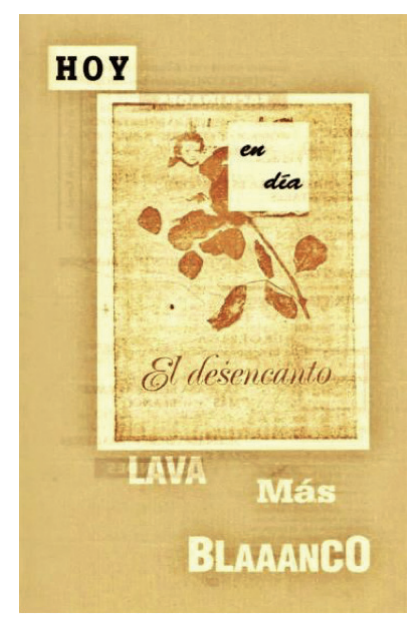

Figura 4. El desencanto lava blanco.

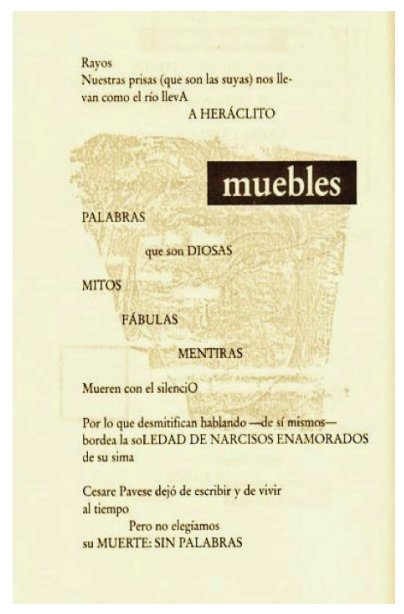

Figura 5. Palabras que son diosas.

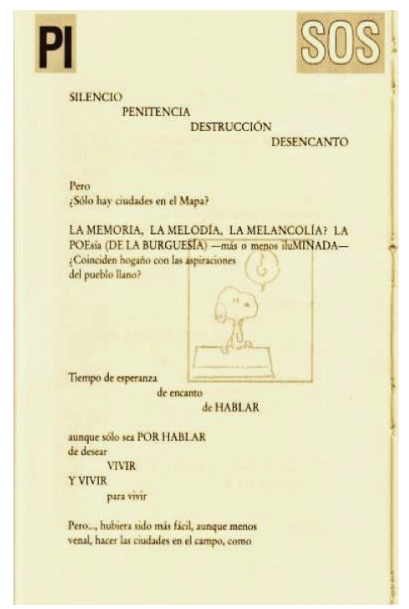

Figura 6. PI SOS snoopy.

Y terminamos con otro texto también de $H O Y$ en día... donde la crítica no es solamente socioeconómica, aunque aparece la especulación urbanística en los cartuchos-anuncios de pisos separando "PI" y "SOS" sugiriendo una llamada de auxilio, y en la referencia a las ya incipientes urbanizaciones en las afueras de las ciudades, sino de un amplio espectro social y ambiguamente política en la alusión a la burguesía “¿Coinciden hogaño con las aspiraciones / del pueblo llano?", a un futuro "tiempo de esperanza" y de libertad "de desear / VIVIR / Y VIVIR / para vivir". En cuanto a este lenguaje, aparte del trato marcadamente publicitario, hay alusiones y un uso de la lengua cotidiana, oral por la inclusión del poeta como narrador, y expresiones populares, "hablar por hablar", así como de canciones populares como 
«Para vivir» editada por Serrat en 1974. Por último el uso de una viñeta de cómic remata la manipulación poética de los textos alejianos, porque se aprecia cómo se vincula, —collage y semióticamente-, con el resto del texto lingüístico al hacer referencia a la sorpresa y la interrogación a la que también alude todo el texto. Una muestra más del uso de ese lenguaje vanguardista en el que los elementos cotidianos que utiliza son expresión de la sociedad en la que vive, que utiliza para aprovecharlos en beneficio de un mensaje serio para desenmascararlos, y a la vez hacer una crítica de todo el sistema, incluyendo al ser humano que se deja convertir en una marioneta sirviendo a unos intereses socioeconómicos alejados de las cualidades y los valores humanos.

\section{CONCLUSIONES}

Los modos y maneras de la poesía vanguardista de Justo Alejo ya hemos visto a través de sus versos que no encajan estrictamente en los típicos planteamientos de la vanguardia histórica, porque siempre pretende tender un puente comunicativo, a través de la palabra como eje principal, con el lector. Un lector, que para Alejo no es abstracto, un elemento más de la comunicación, sino alguien cercano a quien convencer y hacer sentir, que debe cambiar su actitud en la sociedad rompiendo sus relaciones - impuestas y aceptadas - con los intereses de las grandes empresas, tomando conciencia del poder alienante que tiene la Tv, como generador de individualismo y soledad. Por eso ese lector será la causa de que los elementos lingüísticos vanguardistas que usa se los proporcione la lengua oral y la publicidad y no símbolos abstractos o conceptuales.

Y es que Alejo no se centra únicamente en un nuevo lenguaje, sino en una nueva comunicación, poniendo un foco de atención especial sobre el receptor del mensaje; y, claro, en el lenguaje, pero un lenguaje donde es fácil reconocer rasgos y elementos vanguardistas tanto formales, en ese levantamiento de letras y sílabas, el uso y manipulación del lenguaje de la publicidad, como en la generación de relaciones semánticas y semióticas sorprendentes entre las palabras, en un plano paradigmático y sintagmático, y sugiriendo mediante sus asociaciones y situaciones nuevas en la cadena del lenguaje, una realidad más abierta y caleidoscópica, y unas relaciones más abiertas también con el lector, que debe participar en el proceso comunicativo para completarlo y darle su sentido pleno. Rasgos vanguardistas que integran finalmente en sola / MENTE... su honda preocupación por una comunicación más completa con su crítica, que busca implicar incluso al lenguaje en toda expresión real o hipotética, y que culmina en los agujeros que tienen una fuerte expresión semiótica y conceptual de un lenguaje de raíz filosófica ${ }^{21}$. Trata así Alejo de buscar una mejor expresión formal, indagando en la filosofía a través de la autorreflexión sobre el contenido de la —su- poesía y sobre todo acerca de los escasos resultados del poder transformador de la poesía sobre la realidad. El libro es todo un ejercicio de humildad, sencillez y utopía, que no ceja en su intención, a pesar de la contradicción aparente, al abrir y cerrar todo el poemario con un refrán, trastocado a su manera, que es todo un planteamiento para su obra: "palabras son amores" y "palabras sean

\footnotetext{
${ }^{21}$ Recordemos su formación en Filosofía, Sicología o Sociología.
} 
amores". ¿Da a entender con ello que las palabras son como los hechos — las obras — según el refrán? ¿O como el refrán incita a que deben ser hechas realidad, y no quedarse solo en las intenciones? Quizás también en el propio sentido de vanguardia está la soledad al representar la vanguardia el hecho de estar adelantado a los demás y por ende solo; o quizás Justo Alejo recoge lo que ya intuyeron Baudelaire y Mallarmé, e incluso Walter Benjamin: que la situación de una sociedad centrada en la ciudad como un escaparate comercial y en unas relaciones humanas meramente económicas solo lleva a un vacío. Muchos quizás para una obra como la de Alejo que en sí es en muchas ocasiones una metáfora pura sin término real.

Si como dice Barthes (1993:263-64) “[...] La semiología nunca postula en la actualidad la existencia de un significado definitivo. Lo cual quiere decir que los significados son siempre significantes para los otros, y al revés [...]", pensamos que para Alejo en la poesía, como en la vida, todo es igual y lo mismo pero todo es distinto cada día, por efecto de la praxis, el vivir; y más si la intención poética y crítica es mantener abierto — palabras sean amores, según escribió- el canal comunicativo para que fluyan pensamientos y sentimientos, en la realidad física y en la del poema — o en la poesía como expresión necesaria para el ser humano— por encima de cualquier otra consideración teórica que no esté imbricada en la vida cotidiana. Motivos creemos más que suficientes para reivindicar la consideración de vanguardista para Justo Alejo y darle un puesto de relieve en la historia de la poesía más creativa del siglo xx.

\section{REFERENCIAS BIBLIOGRÁFICAS}

Alejo, Justo (1969): serojos luNARES (NIMBOS), Valladolid: Ed. del autor.

- (1971): monuMENTALES REBAJAS / (tristes tópicos) /subMINIFIESTO NORMAL, Valladolid: Ed. del autor.

- (1974): Separata de Lo Mismo, Valladolid: Ed. del autor.

- (1976): Son / netos /// son ecos, Valladolid: Ed. del autor.

- (1976): HOY / en día / El desencanto / LAVA Más BLAAANCO, (ed. a ciclostil del autor).

- (1978): sola- / MENTE / unas / PALABRAS / libro de horas / y orificios, Valladolid: Ed. del autor.

- (1980): El aroma del viento, Madrid: Ayuso .

- (1990): «Doce dulces sonetos y en prosa», Poesía. Revista ilustrada de información poética n. ${ }^{\circ} 33$, Madrid: Ministerio de Cultura.

- (1997): Poesía (2v), Valladolid: Fundación Jorge Guillén.

Amón, SANTIAGo (1971): "Prólogo" de monuMENTALES REBAJAS / (tristes tópicos) /subMINIFIESTO NORMAL, Valladolid: Ed. del autor.

Armero, Gonzalo (1972): "Sobre una recopilación iconoclasta de Justo Alejo Oceános", Trece de Nieve n. ${ }^{\circ}$ 3, p. 30-31, Madrid.

Barthes, Roland (1993): La aventura semiológica y la publicidad Barcelona: Paidós, (2aed.) (también en http://perio.unlp.edu.ar/catedras/system/files/barthes_roland_-_la_aventura_semiologica. pdf [17/08/2015].

Baudelaire, Charles (1985): Pequeños poemas en prosa, (Traducción y prólogo: Marco Antonio Campos), México: Ediciones Coyoacán.

Benjamin, Walter (2005): Libro de los pasajes, [Rolf Tiedemann, (ed)], (Traductores: Isidro Herrera Baquero, Luis Fernández Castañeda, Fernando Guerrero), Madrid: Akal.

CózAr, RAFAEL DE, (1991): POESÍA E IMAGEN. Poesía visual y otras formas literarias desde el siglo IV aC. hasta el siglo XX, Sevilla: El Carro de la Nieve. 
Cózar, Rafael de (1995): "Caligramas, emblemas, laberintos: los límites de la poesía" III Discusión sobre las Artes. Artes y Literatura. 3, http://www.upv.es/ev/secciones/r_cozar_03.html, [22/07/2015] Grupo de Investigación y docencia Elástica variable. Valencia: Ed. UPV.

Díaz Rojo, José ANTONIO (2002): "El fonosimbolismo: ¿propiedad natural o convención cultural?”, Revista electrónica de estudios filológicos. n. ${ }^{\circ}$ 3, http://digital.csic.es/bitstream/10261/3663/1/ estudiosFonosDiazRojo.pdf [20/08/2015].

Frühbeck Moreno, Carlos (2003): Justo Alejo: una escritura de vanguardia y compromiso, Valladolid: Azul y Academia Castellano y Leonesa de la Poesía.

Mallarmé, StéPhane (1981): Obra poética II (Traducción de Ricardo Silva Santisteban), Madrid: Hiperión.

Moral, Concepción G. y Rosa M. ${ }^{a}$ Pereda, (1982): Joven poesía española, Madrid: Cátedra.

PADÍN, Clemente (1993): Dificultades Metodológicas en el examen de la Poesía Experimental, http:// www.merzmail.net/dificult.htm [30/07/2015].

Paraíso, Isabel (1990): La Literatura en Valladolid en el Siglo XX 1939-1989, Valladolid: Ateneo de Valladolid, p.181-183.

Rozas, Juan Manuel (1986): "La palabra rota de Justo Alejo", en «Poesía de renovación y experimentación». Literatura Contemporánea en Castilla y León, p.137-143, Valladolid: Junta de Castilla y León

Sarmiento, José Antonio (1990): La otra escritura: la poesía experimental en España, 1960-1973, Cuenca: Ed de la Universidad de Castilla La Mancha.

Serra, Francisco (2006): "Reseña El Libro de los pasajes de Walter Benjamin", Foro Interno, 6, p.155-161, http://revistas.ucm.es/index.php/FOIN/article/viewFile/FOIN0606110155A/7998 [20/08/2015].

TALENS, Jenaro (1989): “De la publicidad como fuente historiográfica: la generación poética española de 1970", Revista de Occidente n. ${ }^{\circ}$ 101, p. 107-27, Madrid.

Tiedemann, Rolf (2005): "Prólogo" de Libro de los pasajes, [Rolf Tiedemann (ed)], (Traductores: Isidro Herrera Baquero; Luis Fernández Castañeda; Fernando Guerrero), Madrid: Akal.

Vázquez Montalbán, Manuel (1972): "Elogio a un subnormal”, Triunfo, n. ${ }^{\circ}$ 503, p. 54-55. http://www.triunfodigital.com/mostradorn.php?a\%F1o=XXVII\&num=503\&imagen $=54 \&$ fecha $=1972-05-20$ [28/06/2015].

Vigara Tauste, Ana María (1998): "Función metalingüística y uso del lenguaje", Espéculo 9, http:// www.ucm.es/info/especulo/numero9/fmetalin.html [19/08/2015].

Zunzunegui Diez, Santos (1994): "Pensar la imagen". [Muro, Miguel Ángel (ed.)] Actas del Seminario de Filología Hispánica 1993, p.149-180, Logroño: Gobierno de La Rioja, Consejería de Cultura, Deportes y Juventud.

- (1989): Pensar la imagen, Madrid: Cátedra y Universidad del País Vasco. 